\title{
COVID-19 and Politics
}

\section{Fei $\mathrm{Li}^{1}$, Ching-Han $\mathrm{Liao}^{2}$, Ruoyuan $\mathrm{Ma}^{3}$, Qianyao $\mathrm{Zhu}^{4}$, Yuzhe $\mathrm{Liu}^{5}$}

\author{
${ }^{1}$ Statistics, Michigan State University, East Lansing, United State, Email:941045485@qq.com \\ ${ }^{2}$ Shanghai High School International Division, Baise Road 989, Xuhui District, Shanghai, China, Email: \\ katieliao625@gmail.com \\ ${ }^{3}$ The University of Reading, Reading RG6 6AH, Berkshire, United Kingdom \\ Email :ruoyuan.ma@student.reading.ac.uk \\ ${ }^{4}$ Shenzhen Middle School, Nigang West Road 1068, Luohu District, Shenzhen, Guangdong, China Email: \\ 2123069398@qq.com \\ ${ }^{5}$ Shandong Experimental High School, Jingqi Road 73, Shizhong District, Shandong, China
}

\begin{abstract}
In this project, in this research used the county of Harris and Colorado in Texas, California, and Nevada as examples to investigate the relationship between COVID-19 and the politics of the United States; specifically, the difference in the coronavirus statistics among the counties across the country with varying preferences of the two main political partiesthe Republican Party and the Democratic Party. This paper referenced four databases which are US presidential election county level data, Covid-19 county level data from May 2020 to March 2021, US population data, and county level US latitude and longitude data. In this essay used these data develop a shiny app which contains Country Polarization Map, State Polarization Graph, County Polarization Map, US Covid-19 Death Rate and Confirmed Rate Graph, State Covid19 Death Rate and Confirmed Rate Graph, County Covid-19 Death Rate and Confirmed Rate Graph, and State Covid19 Death Rate and Confirmed Rate Map. In this research used these charts and maps to do some analysis in conjunction with some local policies. The difference in political tendency had little effect on the prevent spread of coronavirus at two counties in Texas, Harris and Colorado. In California and Nevada, Democratic counties in those two states had higher confirmation rates and higher mortality rates than Republican counties.
\end{abstract}

Keywords: United States, Covid-19, US politics, US Coronavirus policies, R Studio.

\section{INTRODUCTION}

Coronavirus disease (COVID-19) is an infectious disease caused by a newly discovered coronavirus. COVID-19 has different effects on different people; most infected people will develop mild to moderate illness and recover without hospitalization. The most common symptoms are fever, dry cough, and tiredness. However, most severely ill patients will have difficulty breathing after 1 week and rapidly progress to acute respiratory distress syndrome, septic shock, difficult to correct metabolic acidosis, coagulation dysfunction, and multiple organ failure [1]. Although countries all around the world have adopted various policies to adapt to the pandemic, unemployment rate and death rate are still significantly high. COVID-19 has hugely devastated the United States, making it one of the countries with the most cumulative confirmed cases and deaths. During the coronavirus outbreak, areas with different political slant have had varying attitudes towards the pandemic, affecting local policies regarding the prevention and measure of the virus. In this project, we used the county of Harris and Colorado in Texas, California, and Nevada as examples to investigate the relationship between COVID-19 and the politics of the United States; specifically, the difference in the coronavirus statistics among the counties across the country with varying preferences of the two main political parties - the Republican Party and the Democratic Party.

\section{ABOUT THE DATA}

Based on our research question, we found four datasets: US presidential election county level data, Covid-19 county level data from May 2020 to March 2021, US population data, and county level US latitude and longitude data. Since our time is very limited, we went to GitHub and found a csv dataset that had already been cleaned up and was ready to go. We decided to use the data from May 2020 to March 2021 for analysis because not only does it overlap with the presidential election, but the time period is also long enough for us to 
observe any possible impact by the new policies. To calculate the infection rate, we extracted a US population dataset. We merged the four datasets together. Fortunately, there is the variable "fips code" in each of the first three datasets that can be used to merge the data. The variable "county" was then used to merge the last data with the first three data. Here is an example of our data after merging together.

Additionally, we made a Shiny App including an introduction, political polarization maps (country, state, and county level), confirmed/death rate plots (country, state, and county level), and county-level confirmed/death rate map to enable users to easily explore our data and the possible correlations among different data.

\section{EXPLORATION AND ANALYSIS}

Since we cannot analyze county level data without dividing it into states for the whole US because we want to observe possible correlation to local policies, we made a confirmed/death rate plot for the whole US and three states including Texas, California, and New York. In the case of Texas, each dot represents a county's data, which is grouped by date into a state's data. All of the counties in the plot are divided according to the outcome of the presidential election into voting Republican or Democratic. If more than half of the population voted for one party, the county would be assigned to that party. We noticed that Texas' data is very interesting. While confirmed rates have been rising, death rates have not. That is why we decided to investigate data in Texas.

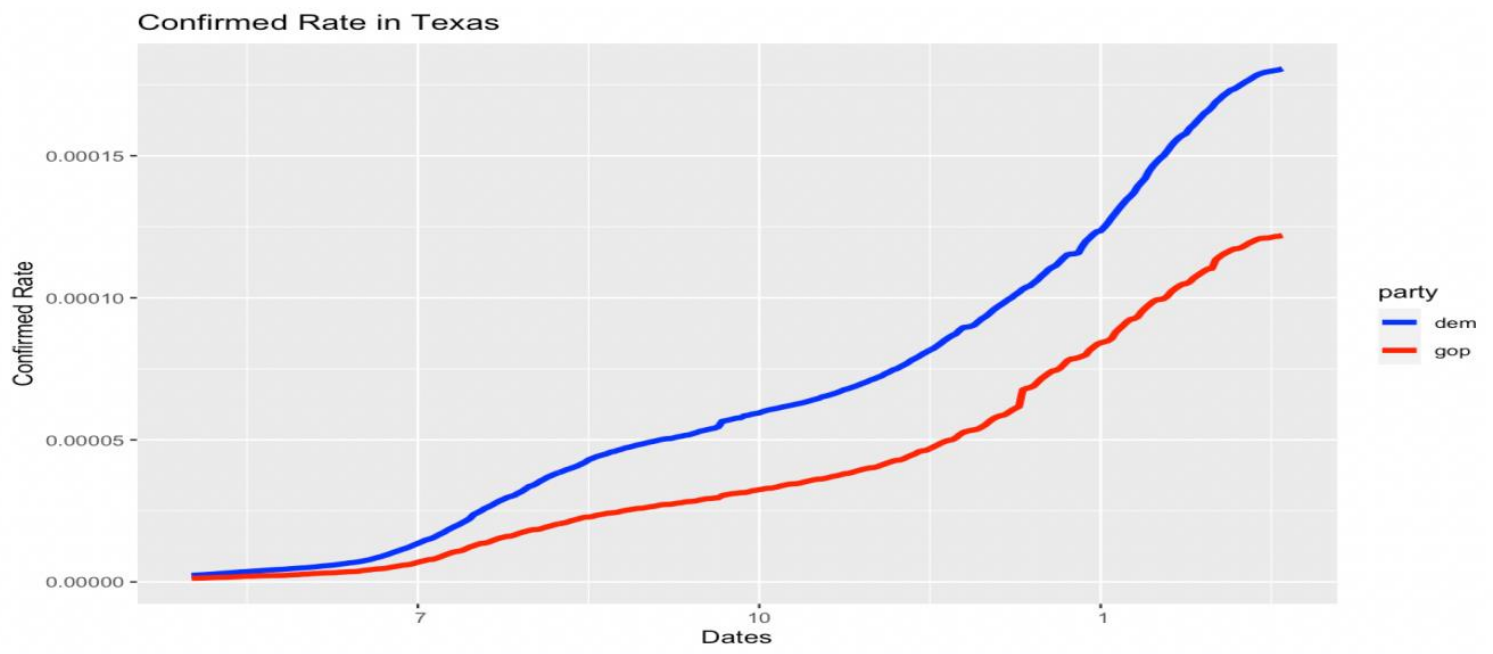

Figure 1. Confirm rate graph in Texas

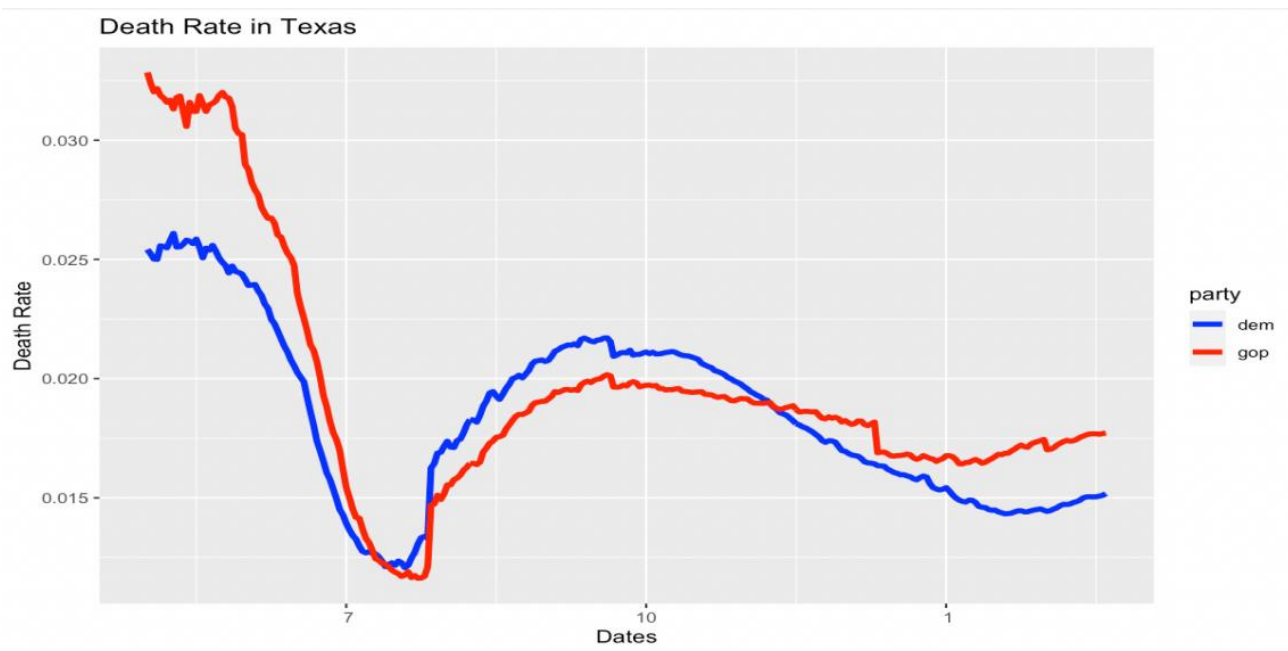

Figure 2. Death rate graph in Texas

One of the things that's really remarkable is that the DSHS began reporting the death based on the death certificate, rather than relying on the figures released by the local and regional health authorities on July 27[2]. Due to this change, it is impossible to compare the death rates before and after July 27 . In fact, by carefully observing the Texas election map that we have made, we can find that most of the counties support the Republican Party. However, it is worth noting that most of the counties that support the Democratic Party are counties with larger scales and larger populations. For example, in Texas, the population of Harris County has the highest cumulative death and confirmed number of people since it is the most populous and largest county. In the 2020 
presidential election, Harris County supported the Democratic Party. Even the current Harris level of risk is Level 1-severe, which means that the level of the Covid19 in Harris County is severe and uncontrolled[3].

The total confirmed number of people in Harris has been rising steadily; yet Harris' death number is not the case. The number of deaths before July 27 is steadily rising. From July 27 to September, Harris' death number rose by about 2,000, a very fast rate. The Governor issued Executive Order GA-30 on September 17, 2020 regarding the continued response to the novel Coronavirus disaster as Texas reopens [5]. From October to January, the growth rate of the death toll began to slow down. During this period, we can see that the government's control has achieved certain results. After the temperature drops, the activity of the virus has also weakened compared to summer. From January to March, however, the death rate began increasing rapidly again. The government recommends that people stay home and work safely. According to Harris' latest regulations, people should still wear masks and keep social distance. According to the Executive Order GA-34 issued by Governor Greg Abbott, it is stipulated that no person in any jurisdiction shall be required to wear or compulsorily wear a mask [4]. Therefore, Harris' policy is essentially to strongly recommend that people wear masks. In fact, masks are no longer restricted in most counties in Texas.

Table 1. data for first day and last day in Harris

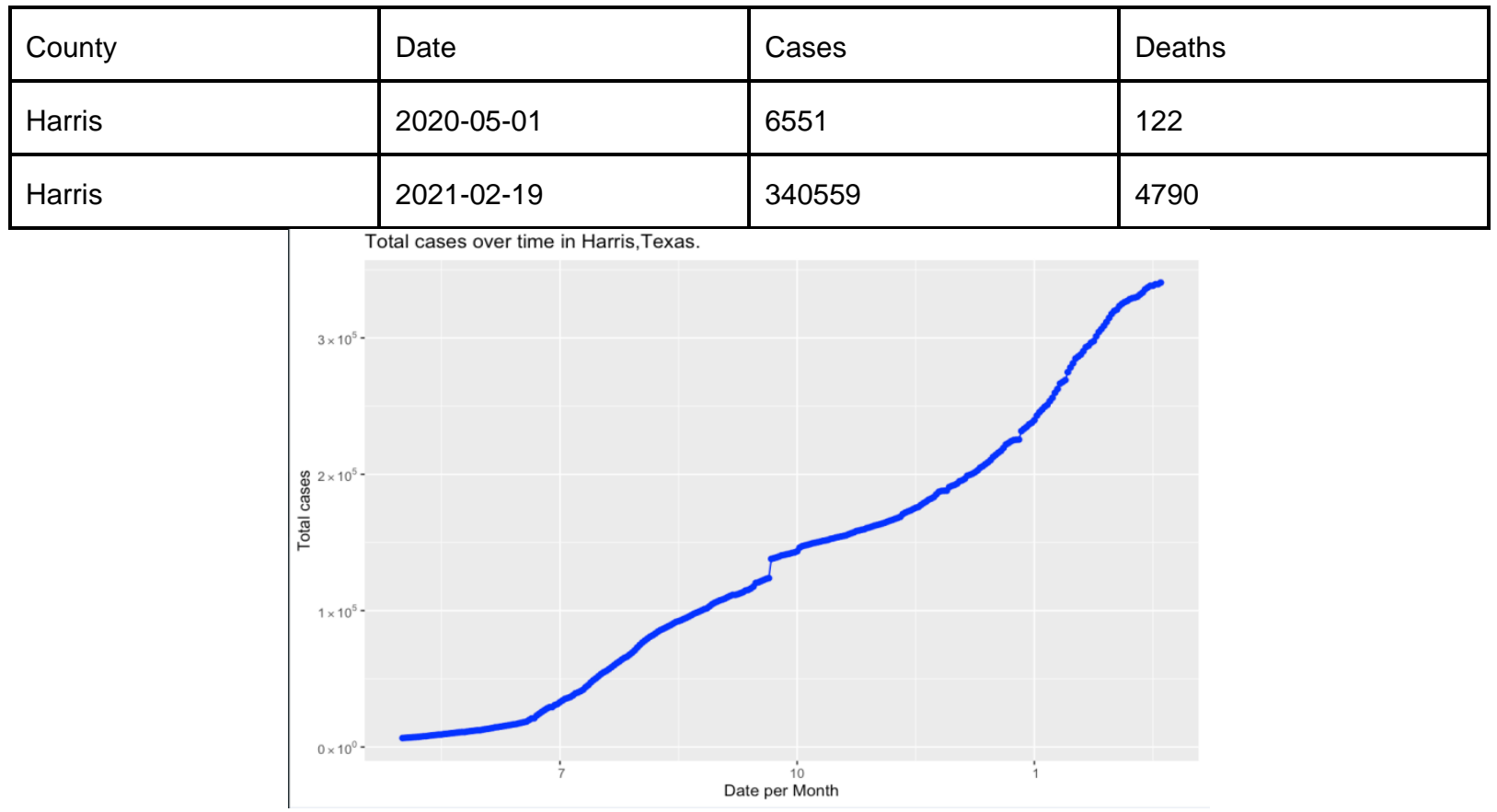

Figure 3. Total cases graph for Harris

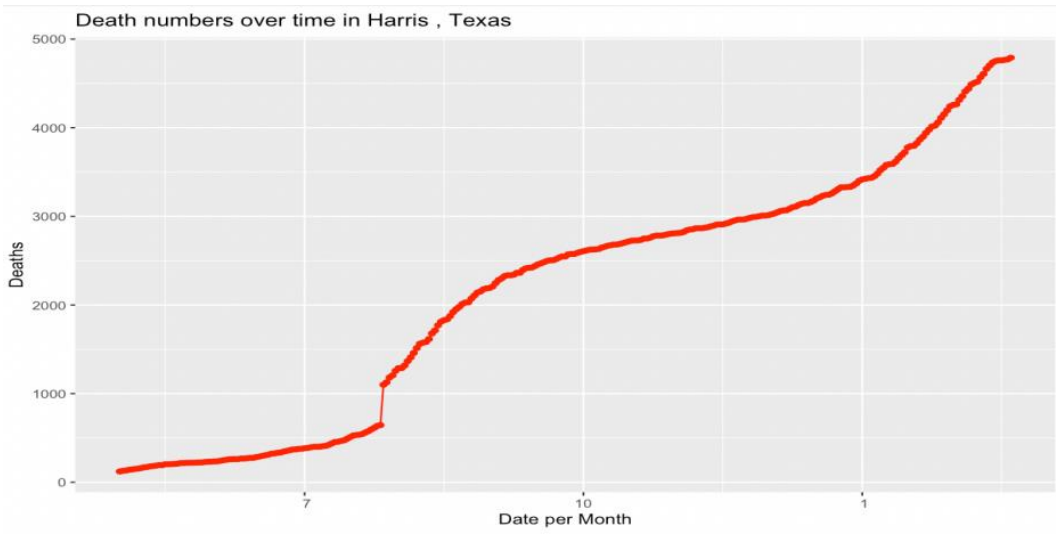

Figure 4. Total Death graph for Harris

On the other hand, we chose to study Colorado as a county that supports the Republican Party for multiple reasons. First, Colorado and Harris are very close, so the geographical environment of the two counties is quite similar. Earlier, we mentioned that, in Texas, most counties that support the Republican party are more rural counties like Colorado. Colorado's total death number and confirmed number growth trend are very similar. The 
number of confirmed cases from May to July increased slowly. The growth rate of confirmed cases between July and September had increased rapidly. During this time, the Covid-19 had begun to become severe in the United States on a large scale and the temperature was also very high. The epidemic in Colorado from September to December was brought under control, so the confirmed cases increased slower. From December to March, the growth rate of the number of confirmed cases increased significantly. It is worth noting that because Colorado has a small population, the total number of deaths is less than 30 , so the total number of deaths is not drawn as a smooth curve, but more like a ladder [6].

Table 2. data for first day and last day in Colorado

\begin{tabular}{|c|l|l|l|}
\hline County & Date & Cases & Deaths \\
\hline Colorado & $2020-05-01$ & 11 & 0 \\
\hline Colorado & $2021-02-19$ & 1507 & 24 \\
\hline
\end{tabular}

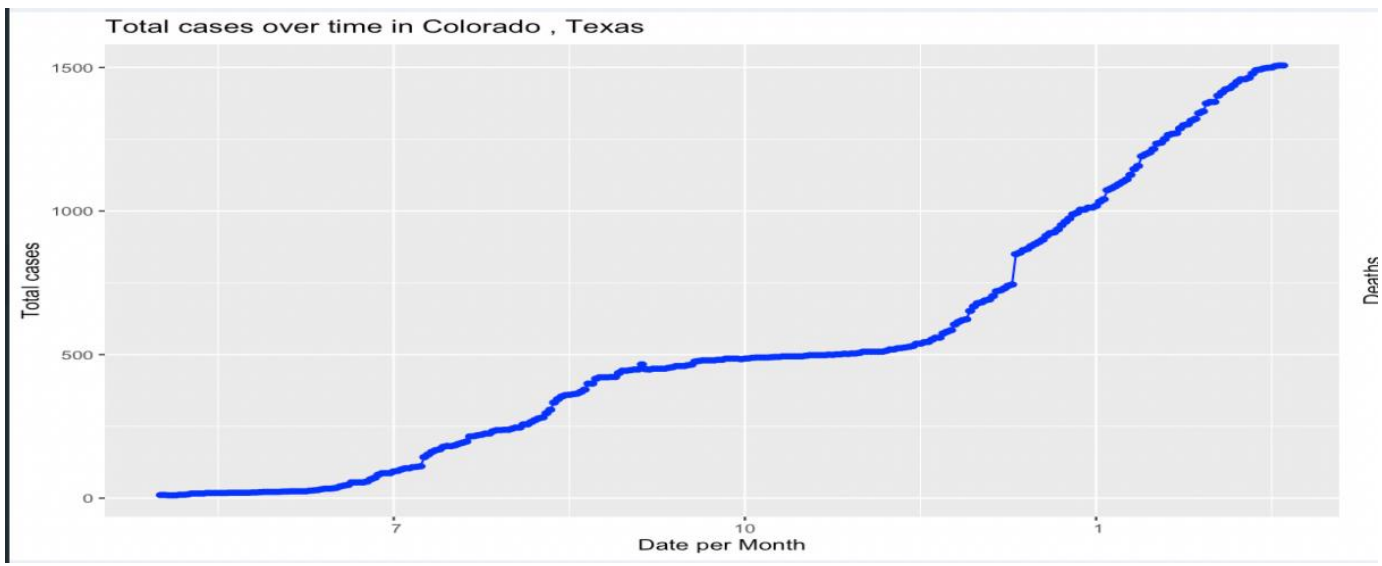

Figure 5. Total cases graph for Colorado

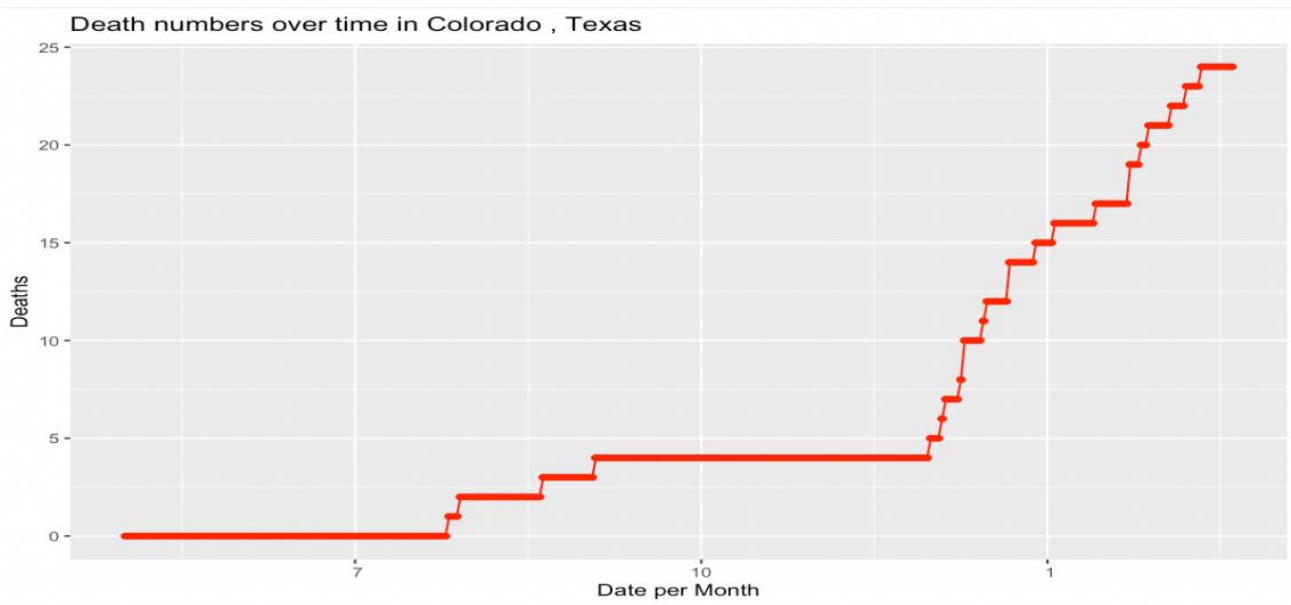

Figure 6. Total Death graph for Colorado

By analyzing Harris and Colorado, we can see that, for counties in the same state, political trends didn't have much impact on COVID-19. The two counties were mostly in similar conditions except that there is a major difference in the number of deaths and the confirmed cases in Harris but not in Colorado. This may be due to the change in the judging criteria for death on July 27. Since the total number of deaths in Colorado is relatively low, the change in the standard did not have a big impact. Now, both counties have now entered the stage of vaccine registration. In the future, as the number of vaccinations increases, the Coronavirus may be brought under control. 


\section{California}

This is the polarization map of the counties of California.

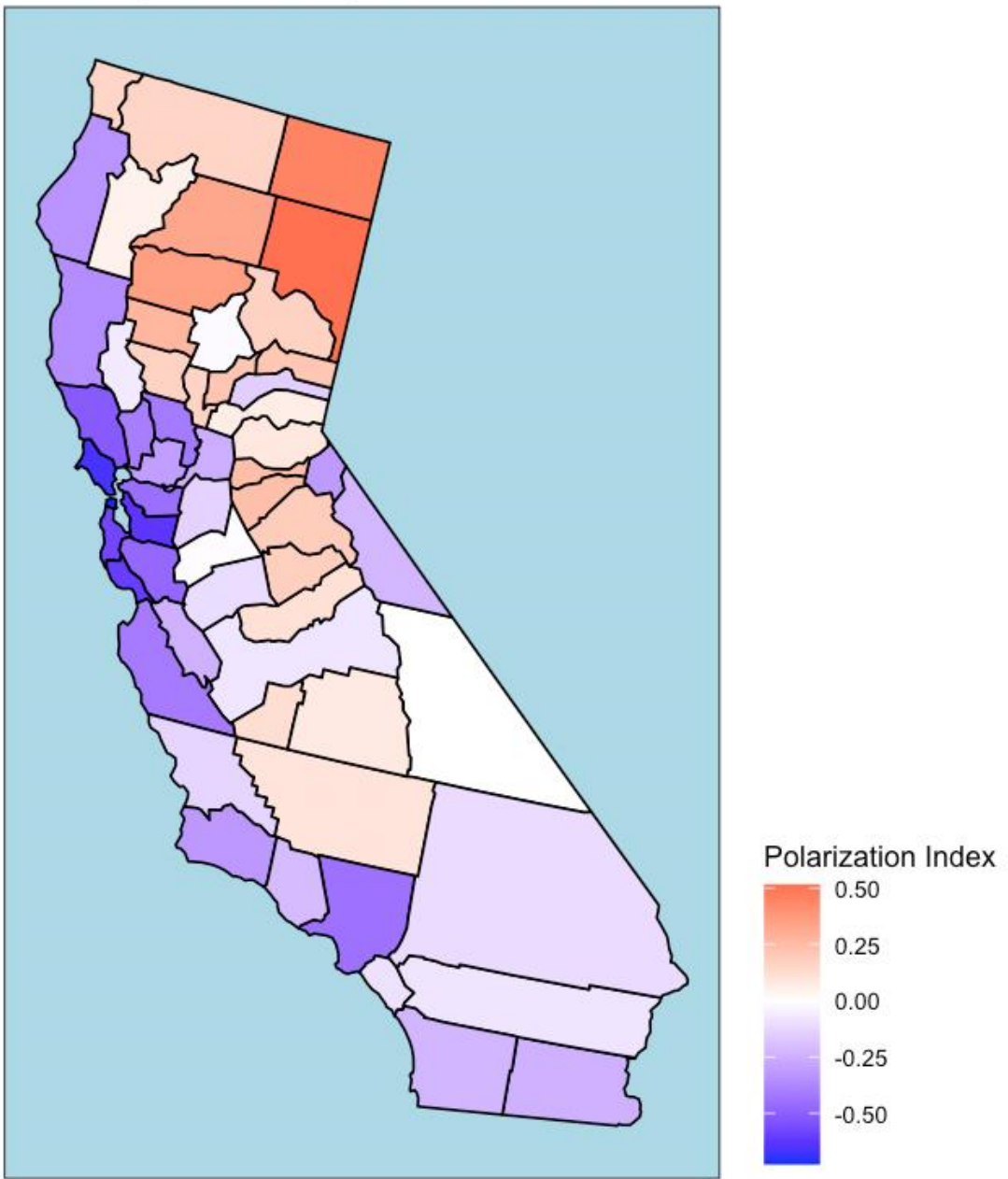

Figure 7. County polarization graph in California

\section{Confirmed Rate in California}

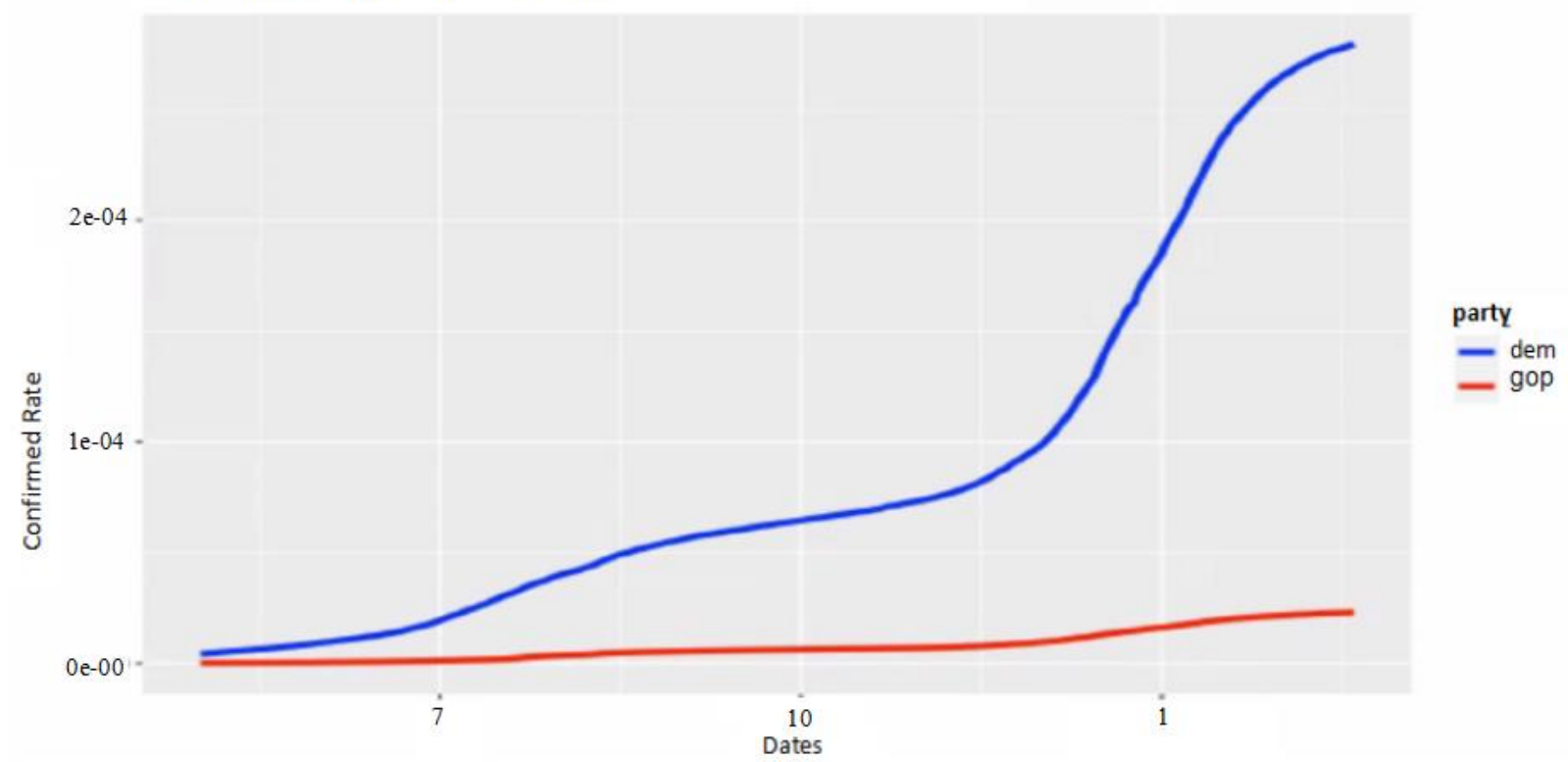

Figure 8. Confirmed rate graph in California 


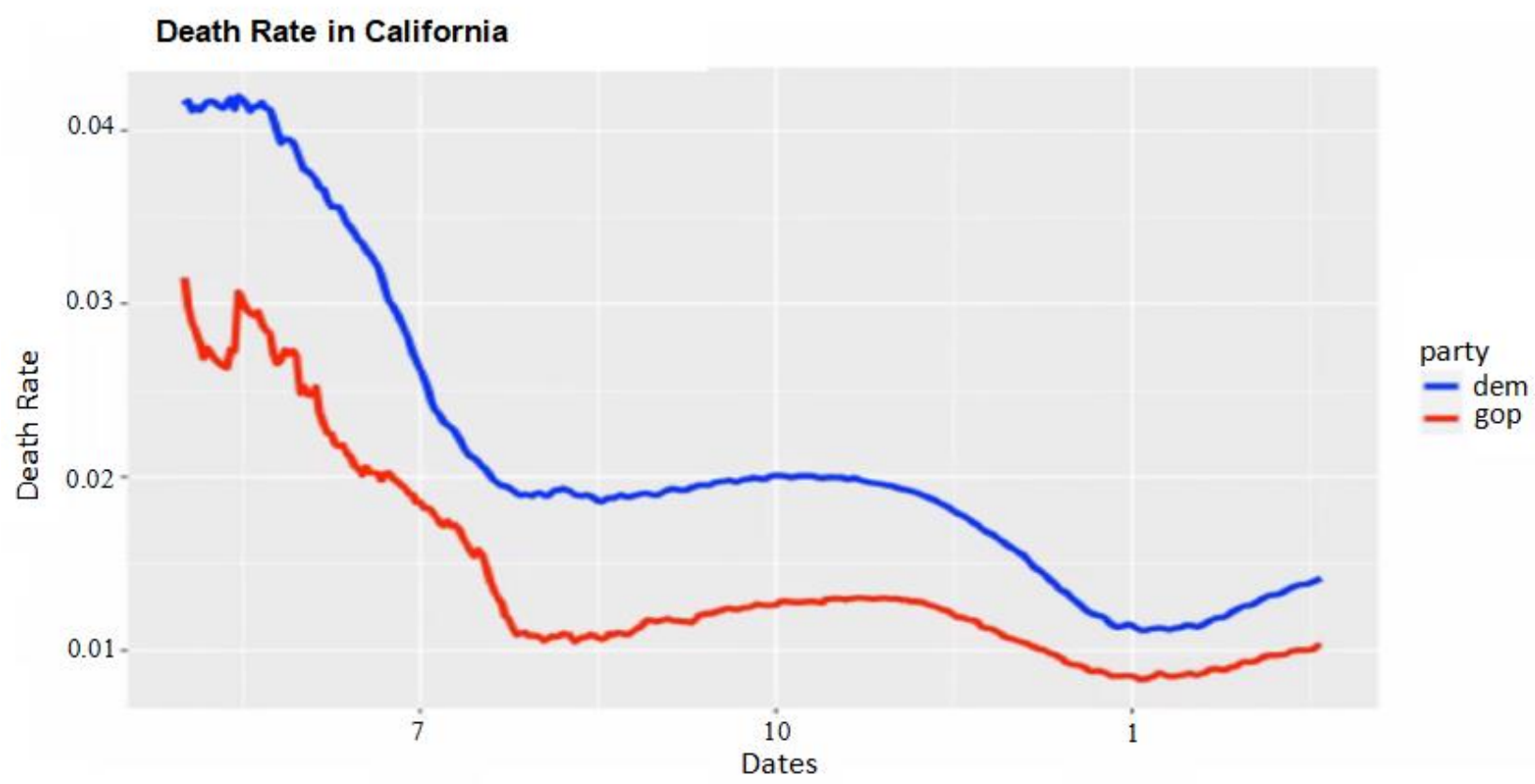

Figure 9. Death rate graph in California

We also analyzed the data of confirmed cases and deaths in California. As shown in the graph of confirmed rate in California, the rate dropped dramatically from June to August in 2020. This may be because the DSHS began reporting the death based on the death certificate, rather than relying on the figures released by the local and regional health authorities on July 27 just like Texas [2]. It is worth noting that both the confirmed rate and the death rate of counties that supported democratic party were higher than those of the counties that supported republican party. This may be due to the larger population of the Democratic counties that are more vulnerable to the spread of the virus.

However, some policies did work to reduce the death cases. On June 25th, Newsom proclaimed a budget to support the state's emergency response to the pandemic. The budget could be used to provide personal protective equipment, medical equipment, and necessary services to vulnerable populations [13]. Since there was more money spent on medical equipment, the death rate decreased. Furthermore, the decreased confirmed cases of vulnerable populations also contributed to the reduction in death cases.
From December 2020 to February 2021, there was a dramatic increase in confirmed cases. First, input cases from foreign countries led to a new Coronavirus strain into the state on December 30. Then, on February 1, 2021, the U.K. coronavirus variant spread in Southern California; this variant spread even more rapidly than the original virus. Nine days later, a South African coronavirus strain was found in California. These were major factors that increased the confirmed rate in California [13].

However, the death rate dropped at the same time. One possible reason is that Governor Newsom imposed several new restrictions during this time. On November 16, Newsom announced that nearly all nonessential businesses should close, and that Californians must wear masks outside their home. Three days later, a new curfew, from 10 p.m. to 5 a.m., was in effect. On December 14, the first vaccine arrived in California. On January 27, 2021, Blue Shield of California started to oversee vaccination in California [13]. With the increase of vaccination, the pandemic became less severe, but it still needs some time before the decrease of confirmed rate because of the high population base. 


\section{Nevada}

This is the polarization map of the counties of Nevada.

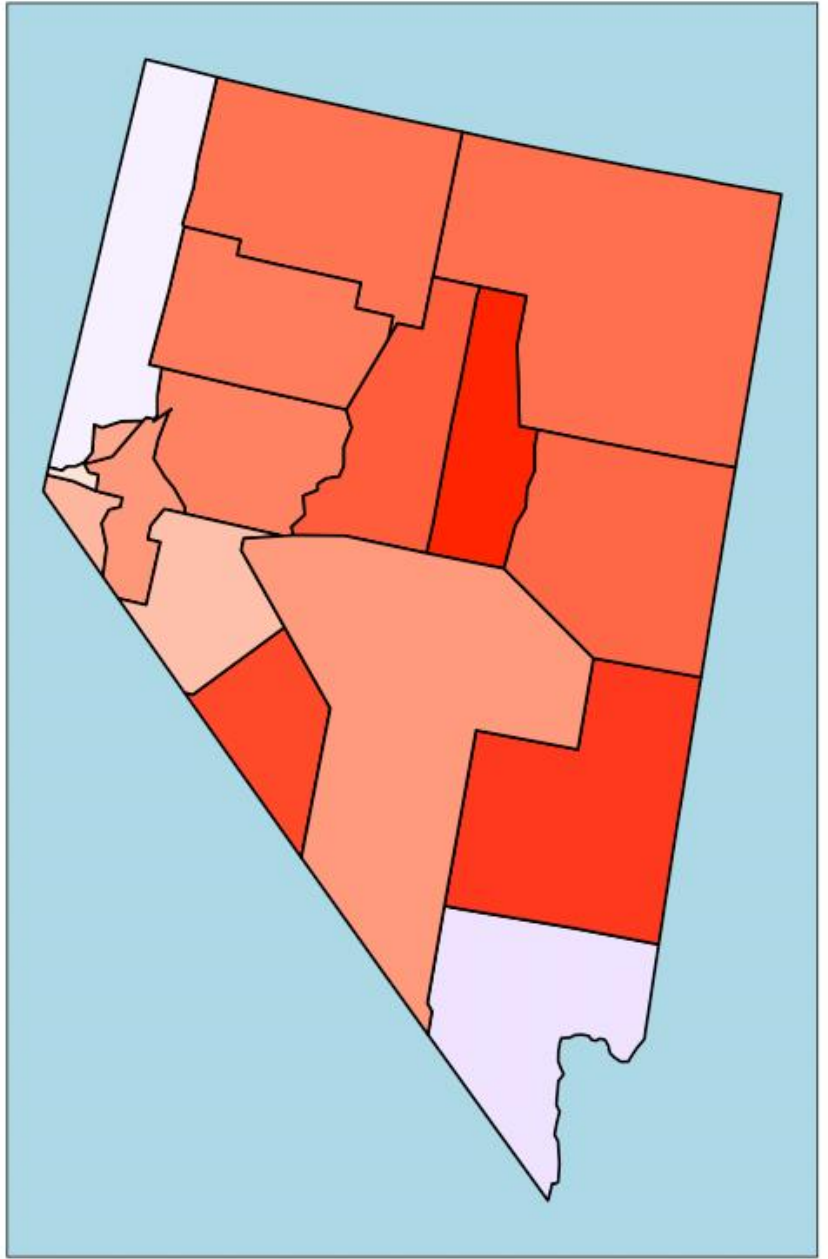

Polarization Index

Figure 10. County polarization graph in Nevada 


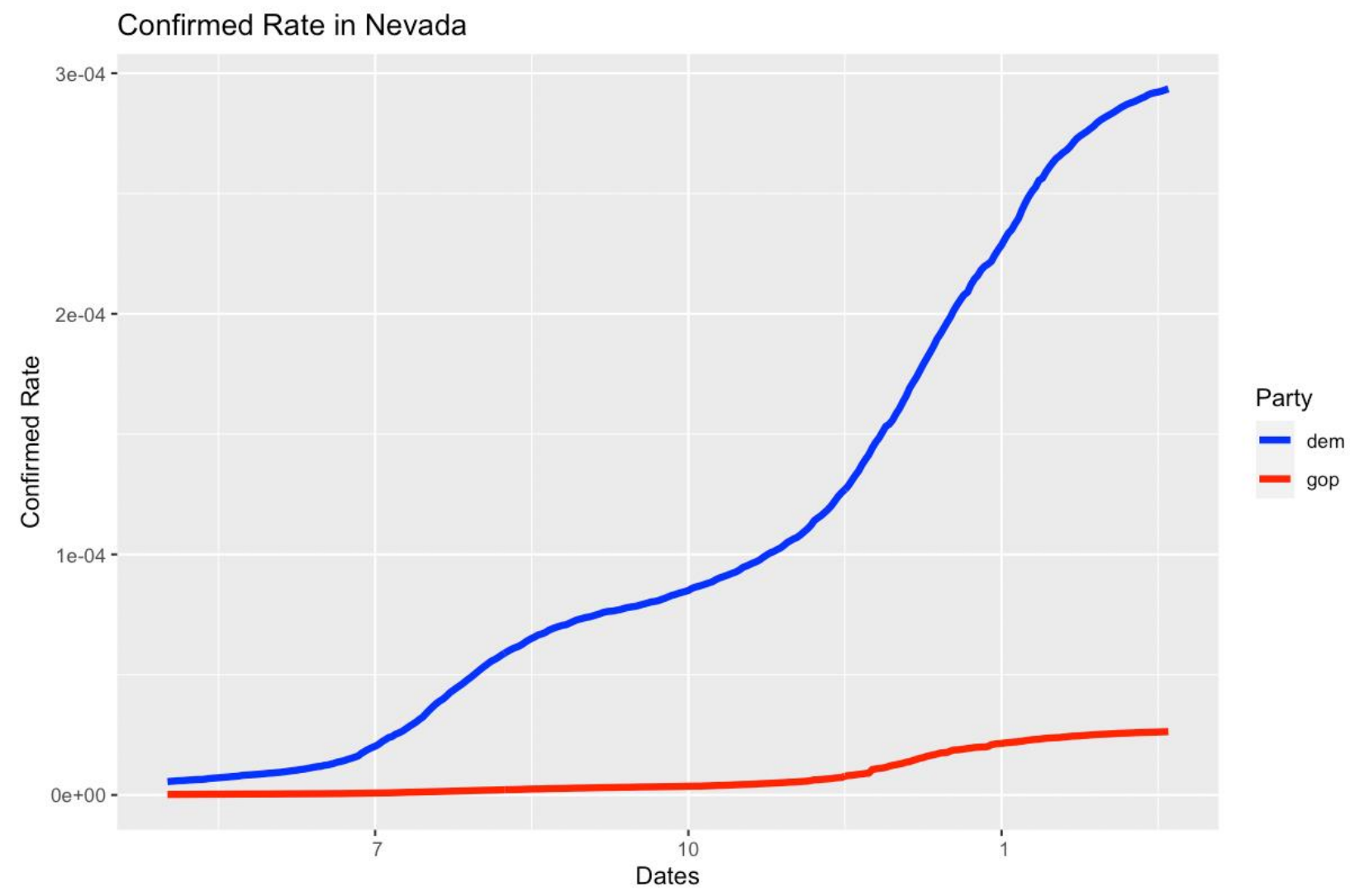

Figure 11. Confirmed rate graph in Nevada

Death Rate in Nevada

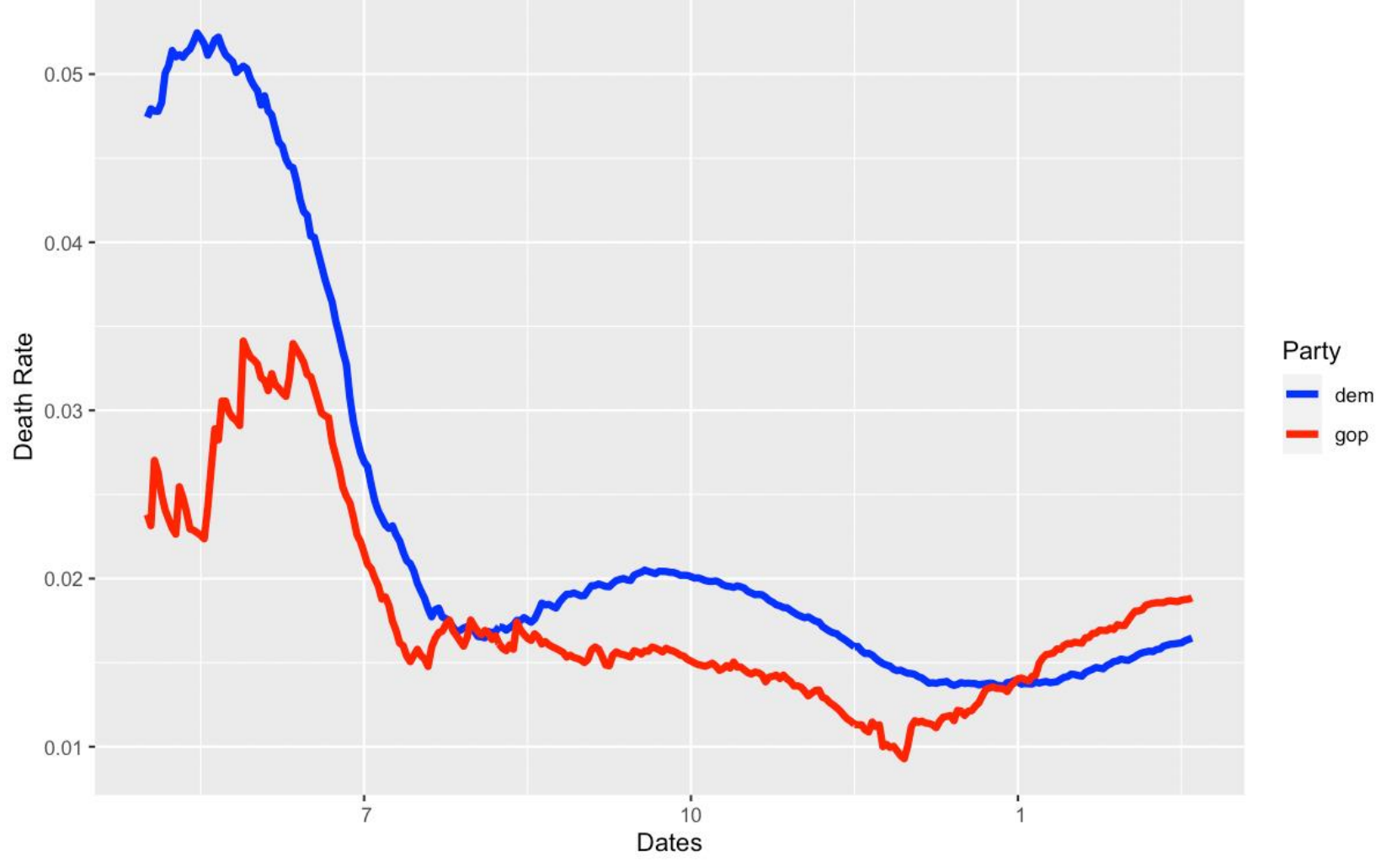

Figure 12. Death rate graph in Nevada 
Moreover, we also observed the situation in Nevada. According to the graphs, both the confirmed rate and the death rate of counties that supported the Democratic Party were higher than those of counties that supported the Republican Party. Although Nevada supported the Republican party overall, the deaths and confirmed rates of counties that supported democratic party were still higher because Clark County, one of the two counties that supported the Democratic Party, has the highest population in the whole state.

The confirmed rate in Nevada increased gradually from July 2020 to February 2021, especially for counties supporting democratic party. There weren't as many policies in Nevada as states such as California. There were policies such as mask wearing and restrictions on gathering [14][15]. These policies were helpful in limiting the spread of Coronavirus but weren't effective enough in helping to slow down the confirmed rate. The death rate in Nevada was almost constant because there wasn't any intensive budget applied to medical needs like the one California had.

\section{SHINY APP}

Firstly, we briefly introduce our research project and give the users an idea of what this Shiny App would be about.

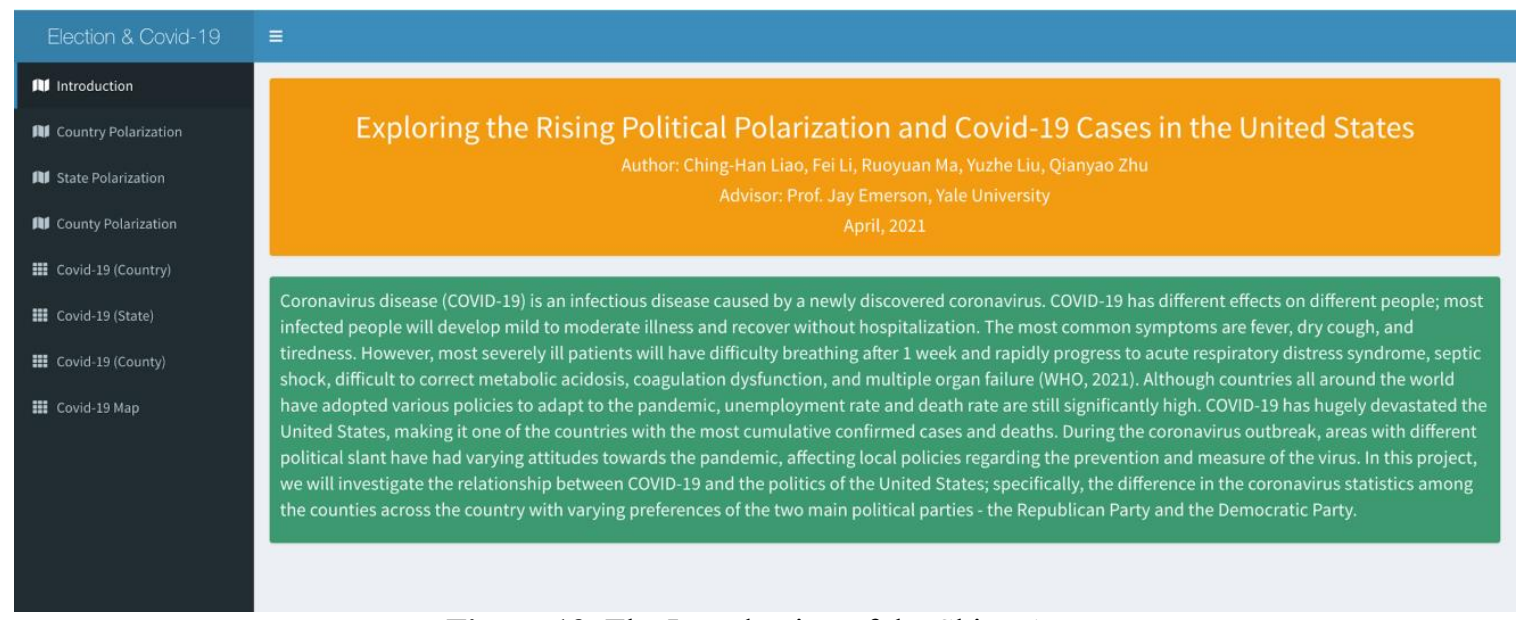

Figure 13. The Introduction of the Shiny App

We used seven packages in total to create all of our maps and plots-"shiny dashboard", "shiny", "maps", "usmap", "ggplot2", “cowplot", “dplyr”, and "scales".

For the polarization maps, we imported the merged data and matched the county names in the packages to the fips code in the data. We used the "per_point_diff" (percentage point difference) column as a standard to measure the political preference of each county in each state. The standard is calculated state by state, meaning that in each state, the counties with relatively high percentage point difference are colored red while the counties with relatively low percentage point difference are colored blue. The more extreme the percentage point difference is, the darker the color will be. In our case, the "red" counties are more supportive of the Republican Party and the "blue" counties are more supportive of the Democratic Party. 


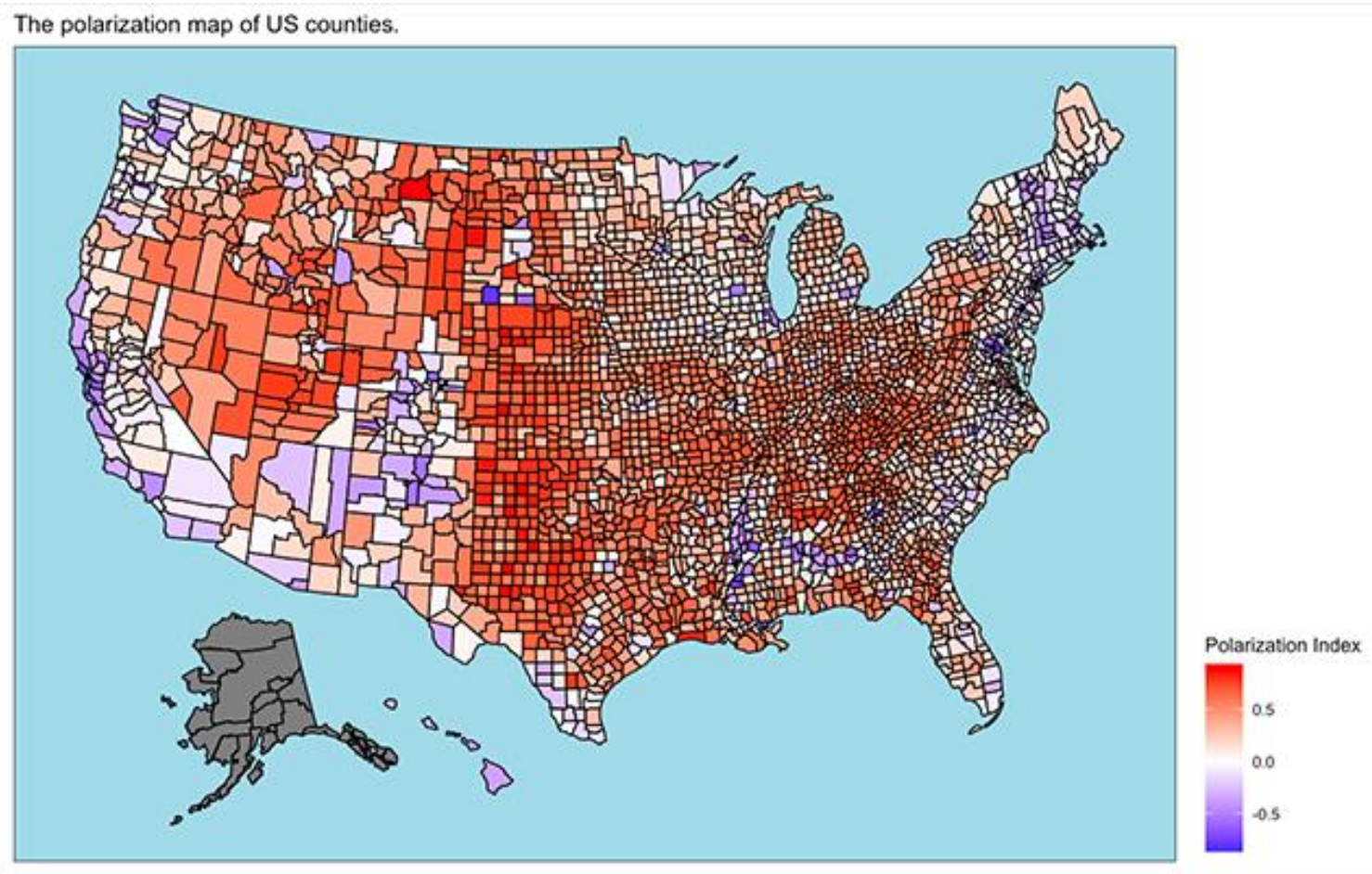

Figure 14. Country Polarization Map

In the "State Polarization" subpage, each state's political polarization is arranged in both alphabetical orders and the scale of support for each party.
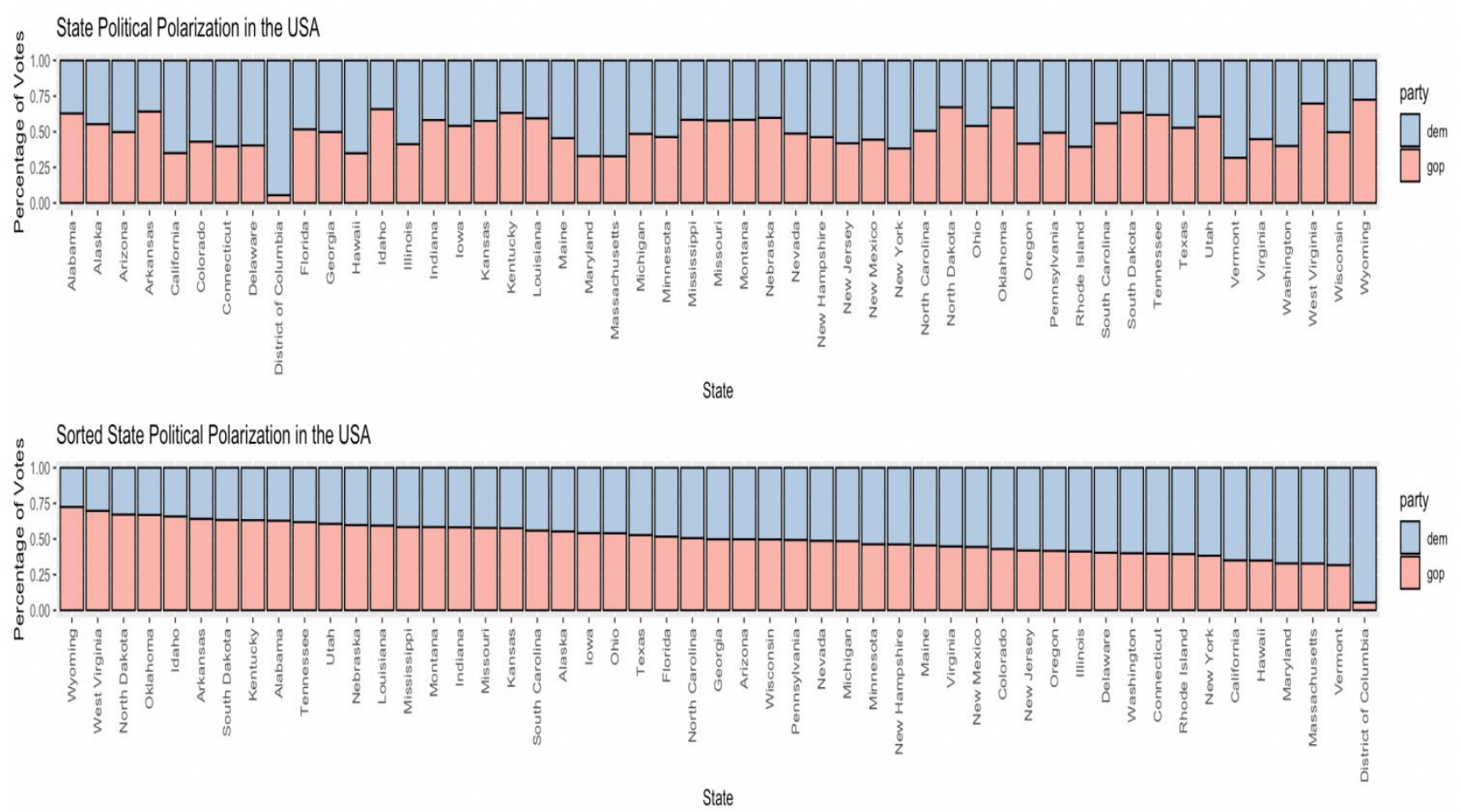

Figure 15. State Polarization Graph

Also, when users choose to add county names on the map in the "County Polarization" subpage, the names will be shown according to the corresponding fips code.
Through the user interface, we also allow users to choose the specific state they want to view. 


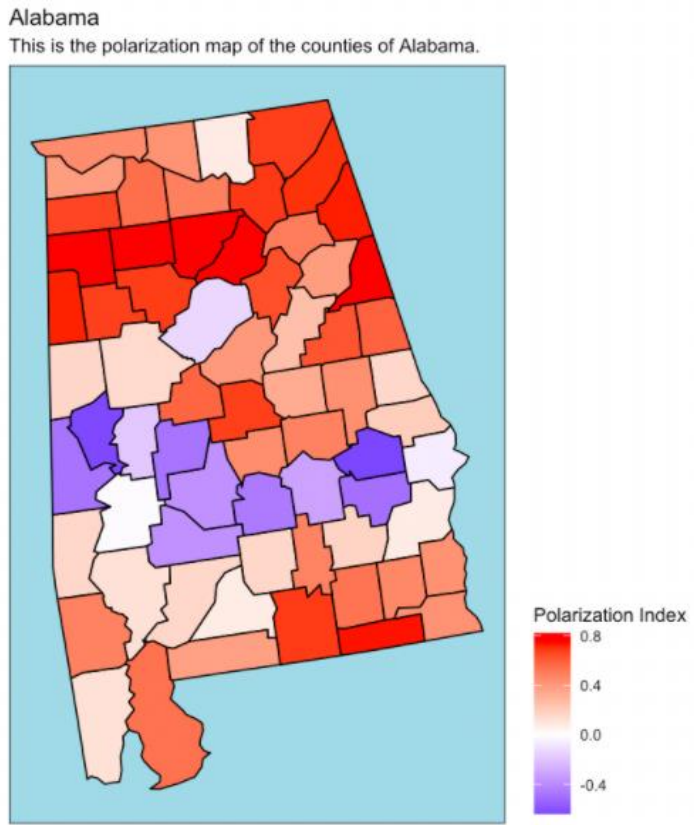

Figure 16. County Polarization Map

As for the COVID-19 confirmed/death rate plot, we classify the counties into two groups--"dem" (Democratic Party) \& "gop" (Republican Party). Each party's confirmed/death rate is the sum of the confirmed/death rates of the counties that they each won in the election.
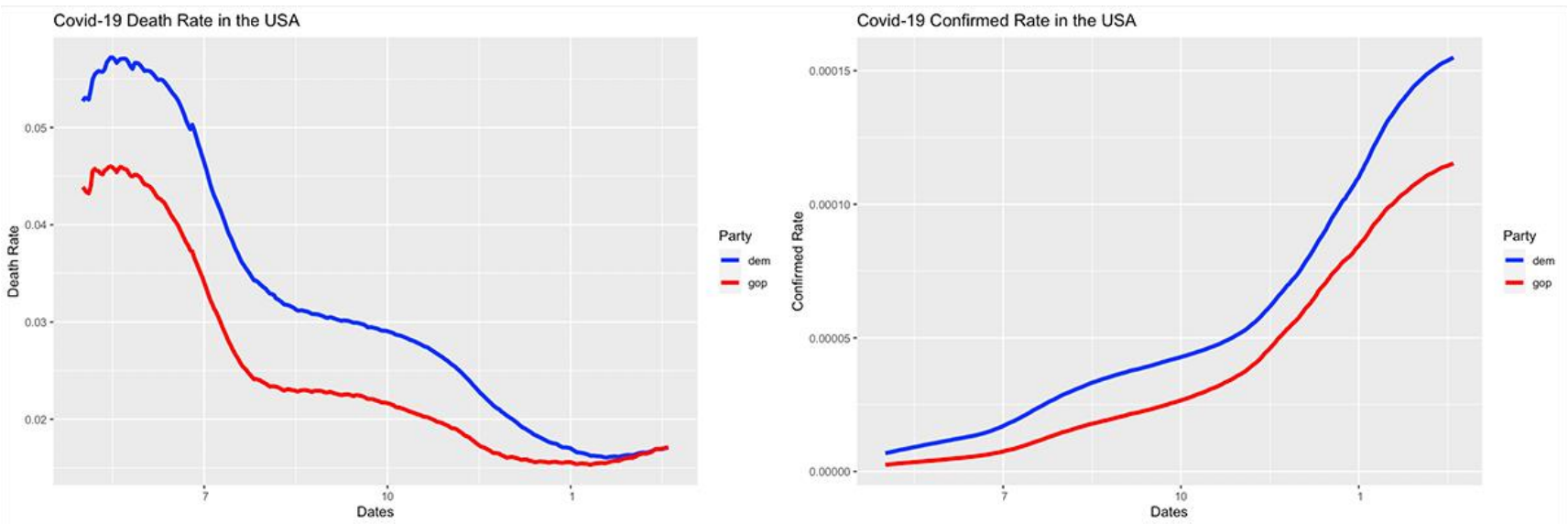

Figure 17. US Covid-19 Death Rate and Confirmed Rate Graph

For the state-level plot, the scale is reduced to each state.
For the country-level plot, the confirmed/death rates of both parties of all the counties in the U.S. are calculated. 

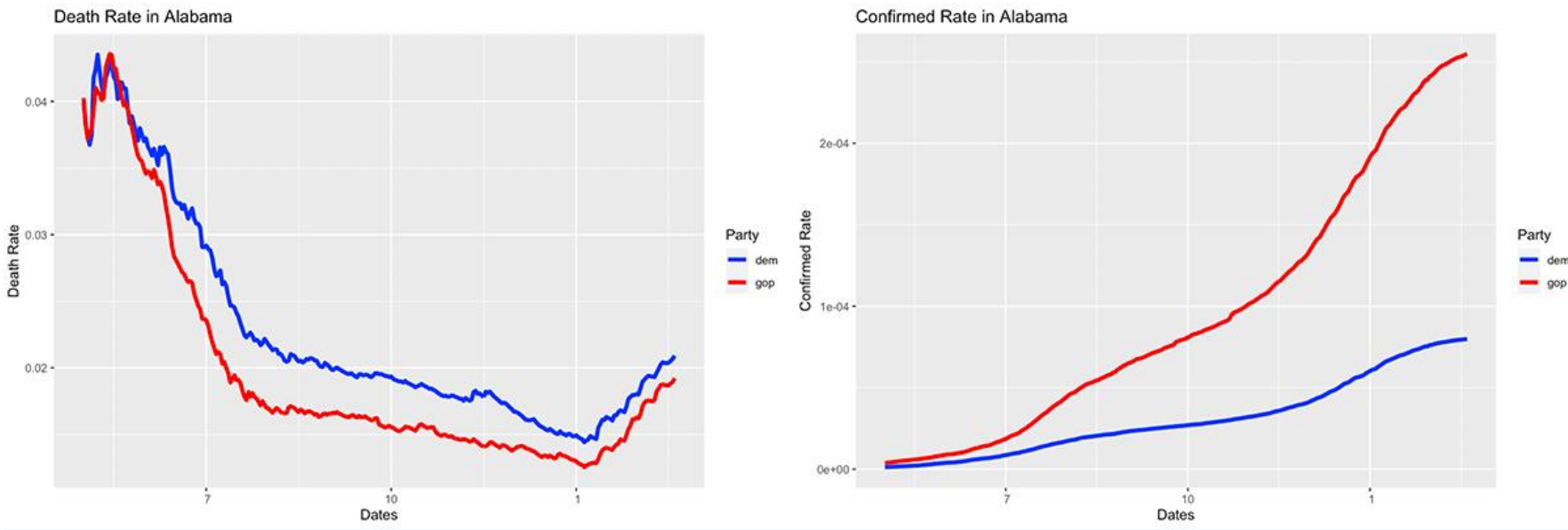

Figure 18. State Covid-19 Death Rate and Confirmed Rate Graph

For the county-level plot, the confirmed/death rates are shown without being classified into different parties because county is the smallest unit in our calculation.
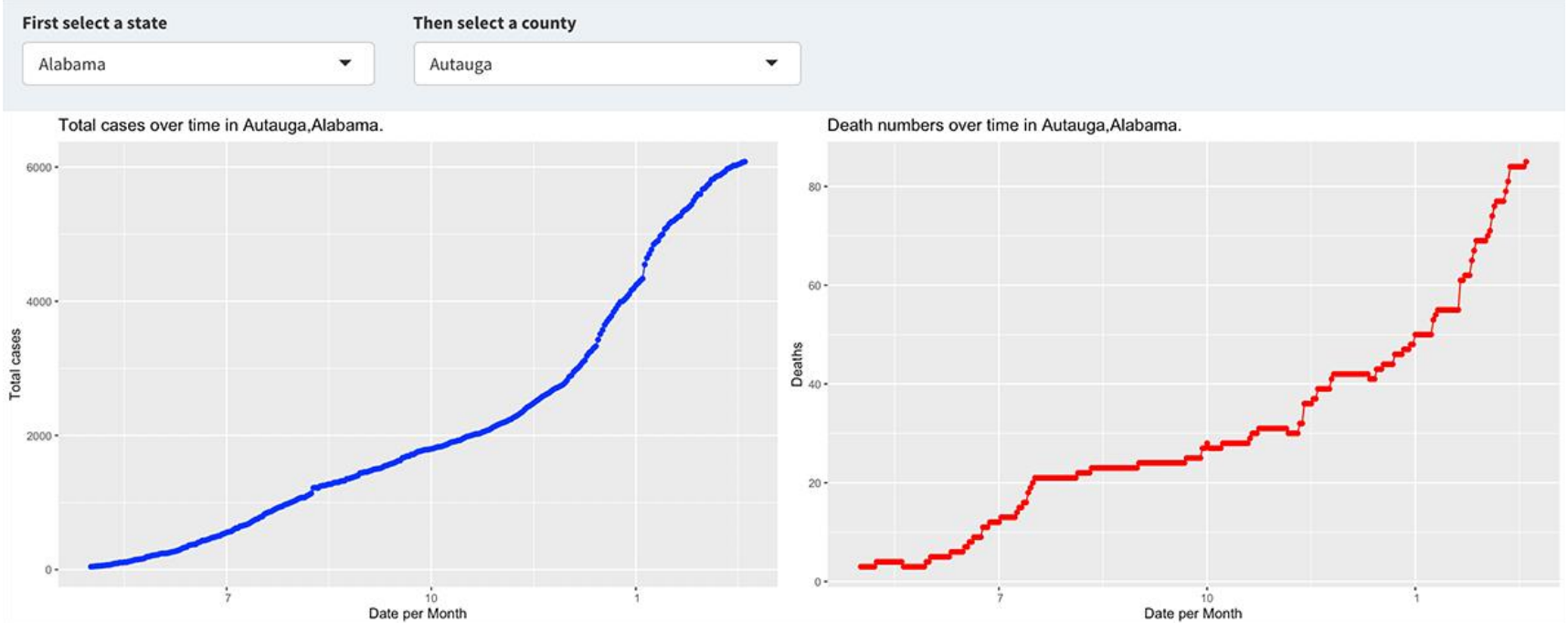

Figure 19. County Covid-19 Death Rate and Confirmed Rate Graph

Lastly, we made a map to show the difference in total confirmed/death rates among each county. The total confirmed/death rates on the map includes the daily confirmed/death rates recorded on the dates within the 11 months our data provides. Moreover, we had to use the natural $\log$ of the total confirmed/death rates in the map instead of the actual numbers because the original numbers were so extreme that the counties were either deep red or deep blue, which makes it very hard for viewers to tell the difference or even compare the confirmed/death rates of different counties. 


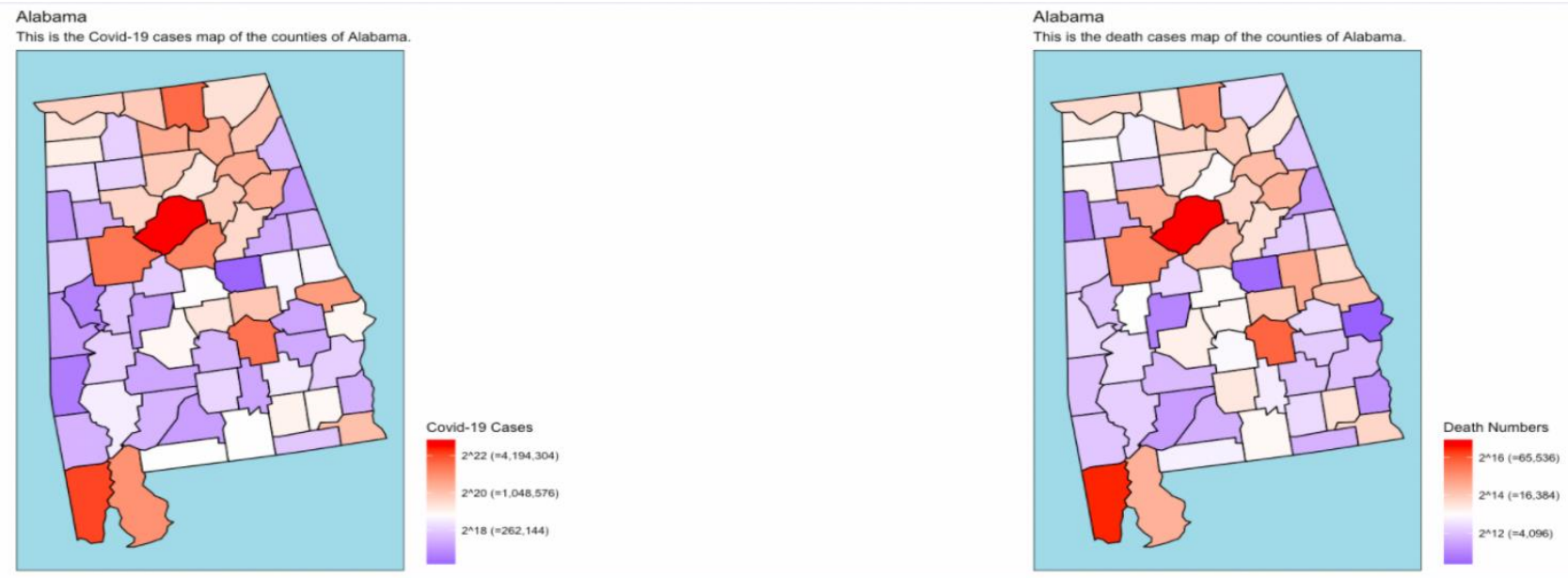

Figure 20. State Covid-19 Death Rate and Confirmed Rate Map

\section{CONCLUSION}

In this report, we used the counties of Harris and Colorado in Texas, California, and Nevada as examples to study how different political tendencies have different attitudes towards the local virus prevention policies. We have discovered that in Harris and Colorado, political tendencies had little impact on the Covid-19. That might be because the policy of the county depends on the entire state to a large extent--even if the political tendencies are different. In California and Nevada, we found that Democratic counties in both states had higher confirmation rates and higher mortality rates than Republican counties. This is likely because Democraticvoting counties have larger populations and are more vulnerable to the spread of the virus. However, our research has potential for further improvement. For example, other counties with different political tendencies in different states can be compared since varying policies can be considered by doing so.

\section{REFERENCES}

[1] Who.int. 2021. Coronavirus. [online] Available at: $<$ https://www.who.int/health-

topics/coronavirus\#tab=tab_1> [Accessed 2 April 2021].

[2] The Texas Tribune. 2021. Texas reports fewer than 3,000 people hospitalized for COVID-19 for the first time since June. [online] Available at: $<$ https://apps.texastribune.org/features/2020/texascoronavirus-cases-map/\#cases-by-county-section> [Accessed 2 April 2021].

[3] Public Health.harris county tx.gov. 2021. 2019 Novel Coronavirus. [online] Available at: $<$ https://publichealth.harriscountytx.gov/resources/ 2019-novel-coronavirus $>$ [Accessed 2 April 2021].

[4] Readyharris.org. 2021. Ready Harris. [online] Available at:
$<$ https://www.readyharris.org/Stay-Safe $>$

[Accessed 2 April 2021].

[5] Texas Department of State Health Services. 2021. Opening the State of Texas. [online] Available at: $<$ https://www.dshs.state.tx.us/coronavirus/opentexa s.aspx $>$ [Accessed 2 April 2021].

[6] Co.colorado.tx.us. 2021. Colorado County, Texas. [online] Available at:

$<$ http://www.co.colorado.tx.us $>$ [Accessed 2 April 2021].

[7] NYTimes Covid-19 Data Bot, and Albert Sun. New York Times, 3 Apr. 2021 [online] Available at: $<$ https:/github.com/nytimes/covid-19-data.git $>$ [Accessed 13 March 2021].

[8] McGovern, Tony. 15 Dec. 2020 [online] Available at:

https://github.com/tonmcg/US_County_Level_Elec tion_Results_08-20.git> [Accessed 13 March 2021].

[9] Yin, Thai. 24 August, 2013 [online] Available at: $<$ https://docs.gaslamp.media/download-zip-codelatitude-longitude-city-state-county-csv/\#'\%20longitude-city-state-county-csv/> [Accessed 13 March 2021].

[10] United States Department of Agriculture Economic Research Service. Available at: $<$ https://www.ers.usda.gov/data-products/countylevel-data-sets/download-data/> [Accessed 13 March 2021].

[11] Shiny App [online] Available at:

$<$ https://github.com/dcorrig1/US_Political_Polariza tion/tree/master/Shiny_App $>$ [Accessed 2 April 2021]

[12] R Core Team (2020). R: A language and environment for statistical computing. R Foundation 
for Statistical Computing, Vienna, Austria. URL https://www.R-project.org/ .

[13] Timeline: California reacts to coronavirus. CalMatters [online] Available at: $<$ https:/calmatters.org/health/coronavirus/2020/04/ gavin-newsom-coronavirus-updatestimeline/\#First\%20case\%20of\%20COVID-

19\%20in\%20California> [Accessed 11 April 2021]

[14] COVID-19 Vaccine Information in Nevada $<$ http://dpbh.nv.gov/Programs/Immunization/COVI D/COVID_Vaccine/> [Accessed 11 April 2021]

[15] Nevada's response to COVID-19 $<$ https://nvhealthresponse.nv.gov/> [

[16] Accessed 11 April 2021] 